\title{
PERANCANGAN SISTEM INFORMASI PEMESANAN CATERING PADA BUNA HOMEMADE BERBASIS JAVA
}

\author{
Fina Agustina Setiono1, Gilang Ryan Fernandes², Iwan Budiarso ${ }^{3}$ \\ ${ }^{1,2,3}$ Universitas Indraprasta PGRI \\ Jalan Raya Tengah No 80, Kelurahan Gedong, Pasar Rebo, Jakarta Timur \\ $\underline{1 \text { agustinasfina@gmail.com, }}{ }^{2}$ gilang.fernandes@ gmail.com, $\underline{3}$ budiarso.iwan@gmail.com
}

\begin{abstract}
ABSTRAK
Kebutuhan teknologi di masa globalisasi saat ini semakin alami perkembangan sangat amat pesat, suatu kemudahan serta moderenisasi sangat dimudahkan guna menunjang bisnis serta kemajuan dari suatu perseroan. Penelitian ini memiliki tujuan yaitu merancang sistem informasi berbasis desktop untuk mendukung pemesanan catering sehingga dapat meminimalisir terjadinya kesalahan dalam pemesanan, hal ini dikarenakan pemesanan yang masih dilakukan dengan di tulis tangan yang membuat kemungkinan terjadinya kekeliruan seperti pesanan yang double, tidak urutnya penerimaan pesanan akibat bertumpuknya nota pesanan pada saat ramai pelanggan yang bisa saja terjadi human error seperti lupa atas pesanan pelanggan. Metode penelitian yang digunakan untuk menganalisis aplikasi yang dibuat adalah observasi dan wawancara. Metode pengembangan sistem menggunakan metode waterfall karena metode ini sangat mudah digunakan untuk melakukan pengembangan. Hasil dari penelitian ini dapat meningkatkan kualitas kerja sehingga dapat mengurangi terjadinya kesalahan dan membuat proses pemesanan catering menjadi lebih cepat, tepat, dan akurat.
\end{abstract}

Kata Kunci: Sistem Informasi, Pemesanan Catering, Java

\begin{abstract}
The need for technology in the current globalization period is increasingly experiencing very rapid development, an ease and modernization is very facilitated to support the business and progress of a company. This research has the goal of designing a desktop-based information system to support catering bookings so as to minimize the occurrence of errors in bookings, this is because the order is still done in handwritten that makes the possibility of errors such as double orders, not order acceptance due to stacking order notes when many customers can occur human errors such as forgetting customer orders. The research methods used to analyze the applications made are observations and interviews. The system development method uses the waterfall method because this method is very easy to use to do development. The results of this study can improve the quality of work so as to reduce the occurrence of errors and make the catering ordering process faster, precise, and accurate.
\end{abstract}

Key Word: Information Systems, Catering Booking, Java

\section{PENDAHULUAN}

Kebutuhan teknologi di masa globalisasi saat ini semakin alami perkembangan sangat amat pesat, suatu kemudahan serta moderenisasi sangat dimudahkan guna menunjang bisnis serta kemajuan dari suatu perseroan. Banyak pemilik usaha kecil yang sudah menggunakan sistem terkomputerisasi, tetapi masih banyak pemilik catering yang belum menggunakan teknologi komputer untuk mempermudah pekerjaannya.

Teknologi komputer sudah menghasilkan data yang lebih akurat ketimbang dengan data yang didapat secara manual. perkembangan teknologi ini yaitu usaha yang bergerak dibidang makanan adalah usaha catering. Catering ialah sesuatu sebutan universal buat para wirausaha dalam melayani pemesanan bermacam berbagai masakan, misalnya buat kegiatan acara, rapat, pertemuan, serta kantin ataupun buat penunjang kebutuhan sesuatu lembaga (Al Hadad, 2020). Menu yang disediakan oleh Catering Buna Homemade berbentuk olahan ayam, sayur-mayur, daging sapi ataupun kambing.

Sepanjang ini penerimaan pesanan catering dilayani lewat tatap muka langsung maupun lewat telepon. Dari sistem yang berjalan saat ini yaitu masih dengan di tulis tangan yang membuat kemungkinan terjadinya kekeliruan semacam pesanan yang double, tidak urutnya penerimaan pesanan akibat bertumpuknya nota pesanan pada saat ramai pelanggan yang bisa saja terjadi human error semacam kurang ingat atas pesanan pelanggan. 
Sistem merupakan suatu kesatuan komponen yang saling berinteraksi dan saling berhubungan untuk memudahkan aliran informasi untuk mencapai suatu tujuan tertentu (Fatoni \& Dwi, 2016). Selain itu, Sistem informasi merupakan sesuatu campuran yang saling berhubungan antara teknologi informasi, menunjang pembedahan, serta kegiatan orang yang memakai teknologi didalam sesuatu organisasi guna tujuan yang ingin dicapai (Hutahaean, 2015: 13).

Pengolahan informasi catering masih dilakukan secara manual, mulai dari proses penerimaan pesanan hingga dengan pembuatan laporan, sehingga kerja jadi tidak efektif dan efisien. Informasi yaitu data yang telah diklasifikasikan maupun diolah untuk digunakan dalam proses pengambilan keputusan. sistem pengolahan data hendak mencerna informasi jadi data ataupun mencerna informasi dari wujud tidak bermanfaat jadi bermanfaat untuk yang menerimanya (Sutabri, 2012: 22).

Tujuan dari penelitian ini adalah merancang sistem informasi berbasis desktop untuk mendukung pemesanan catering pada Buna Homemade sehingga dapat meminimalisir terjadinya kesalahan dalam pemesanan dan dapat memudahkan dalam pelayanan pemesanan catering terhadap pelanggan.

\section{METODE PENELITIAN}

Metode yang digunakan dalam penelitian ini adalah metode penelitian kualitatif bertujuan untuk memahami suatu obyek yang alamiah, atau natural sehingga penelitian ini disebut penulisan naturalistic, agar dapat mengembangkan konsep sensitivitas pada masalah yang dihadapi, dan tidak dimanipulasi oleh penulis. Dalam penelitian kualitatif penulis merupakan selaku instrument kunci, pengambilan ilustrasi sumber data dilakukan berdasarkan tujuan serta berkembang terus, metode pengumpulan informasi dengan triangulasi ataupun gabungan, analisis informasi bersifat induktif ataupun kualitatif, serta hasil penelitian kualitatif lebih menekankan arti dari pada generalisasi (Gunawan, 2013: 4).

Adapun metode pengumpulan data yang digunakan dalam penelitian ini adalah sebagai berikut:

\section{Observasi}

Observasi dilakukan dengan melihat secara langsung aktivitas pembuatan serta pemesanan catering di rumah pemilik usaha catering Buna Homemade guna mengetahui apa yang dikerjakan pada sistem berjalan saat ini.

\section{Studi Pustaka}

Studi pustaka ataupun keputusan bisa dimaksud selaku serangkaian aktivitas yang berkenan dengan tata cara pengumpulan informasi pustaka, membaca serta mencatat dan mencerna bahan riset. Penulis mengumpulkan informasi dari bermacam sumber teks buat menemukan data yang masih berkaitan dengan riset yang dicoba.

3. Wawancara

Wawancara dilakukan dengan tanya jawab secara interaktif untuk mendapatkan data secara langsung dari sumbernya dengan harapan informasi yang diperoleh benar. Penulis mengumpulkan data atau informasi dengan melakukan tanya jawab mengenai

Penulis memilih metode pengembangan sistem memakai tata cara SDLC ataupun kerap disebut sebagai pendekatan air terjun (waterfall). Waterfall ialah model klasik yang simpel dengan aliran sistem yang linier output dari tiap tahap ialah input untuk tahap selanjutnya yang sudah disesuaikan dengan kebutuhan. Model waterfall sediakan pendekatan alur hidup piranti lunak secara terurut diawali dari pengumpulan data, analisis, desain, pengkodean, pengujian, implementasi, dan pemeliharaan (Tabrani, 2018). Berikut alur pengembangan sistem dengan model Waterfall:

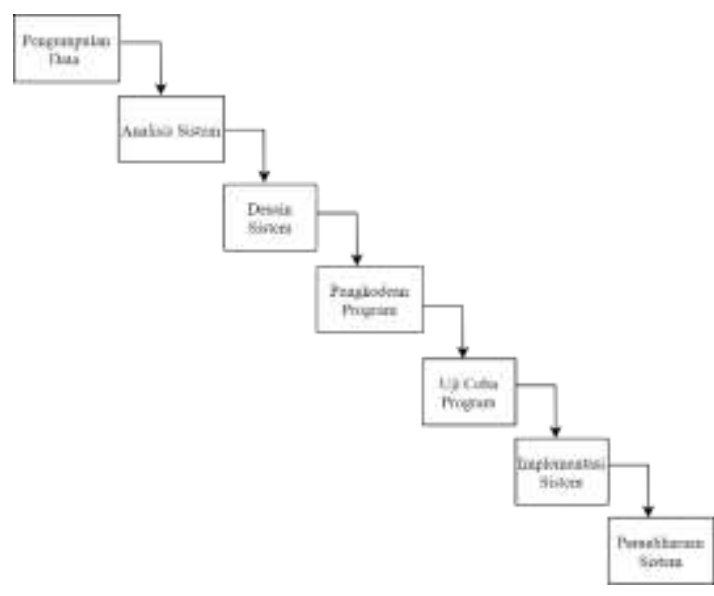

Gambar 1. Gambar Waterfall 


\section{HASIL DAN PEMBAHASAN}

Berdasarkan masalah-masalah yang dihadapi dalam pemesanan catering maka penulis memberikan solusi alternatif penyelesaian masalahnya yaitu, perancangan sistem berbasis java yang diharapkan dapat menghasilkan informasi yang cepat, tepat, dan akurat, data pelanggan, data pesanan, data pembayaran dapat disimpan dalam bentuk database sehingga mudah dalam pengolahannya dan merancang sistem informasi yang dibutuhkan mudah dipahami oleh pengguna agar dapat digunakan oleh karyawan, baik yang memahami komputerisasi maupun tidak.

Berikut ini merupakan gambaran tentang sistem yang diusulkan pada Perancangan Sistem Informasi Pemesanan Catering pada Buna Homemade secara keseluruhan dalam bentuk diagram konteks:

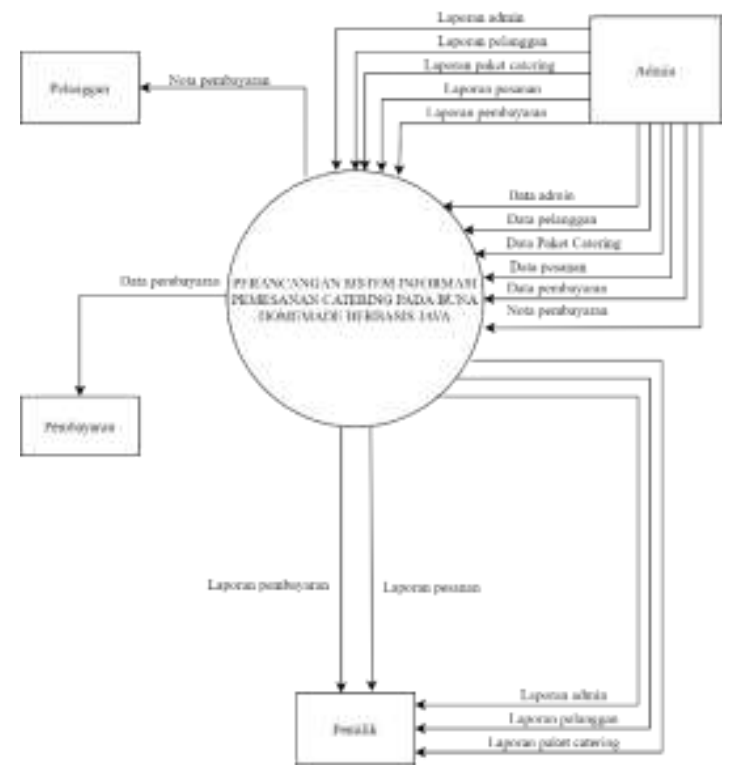

Gambar 2. Diagram Konteks yang Diusulkan

ERD (Entity Relationship Diagram) merupakan model metode pendekatan yang melaporkan ataupun menggambarkan ikatan sesuatu model. Didalam ikatan ini tersebut dinyatakan yang utama dari ERD merupakan membuktikan objek informasi (Entity) serta ikatan (Relationship), yang terdapat pada Entity selanjutnya (Fridayanthie \& Mahdiati, 2016). Selain itu, ERD adalah gambar atau diagram yang menunjukkan suatu informasi yang dibuat, disimpan, dan digunakan dalam sistem bisnis (Tabrani \& Aghniya, 2019).

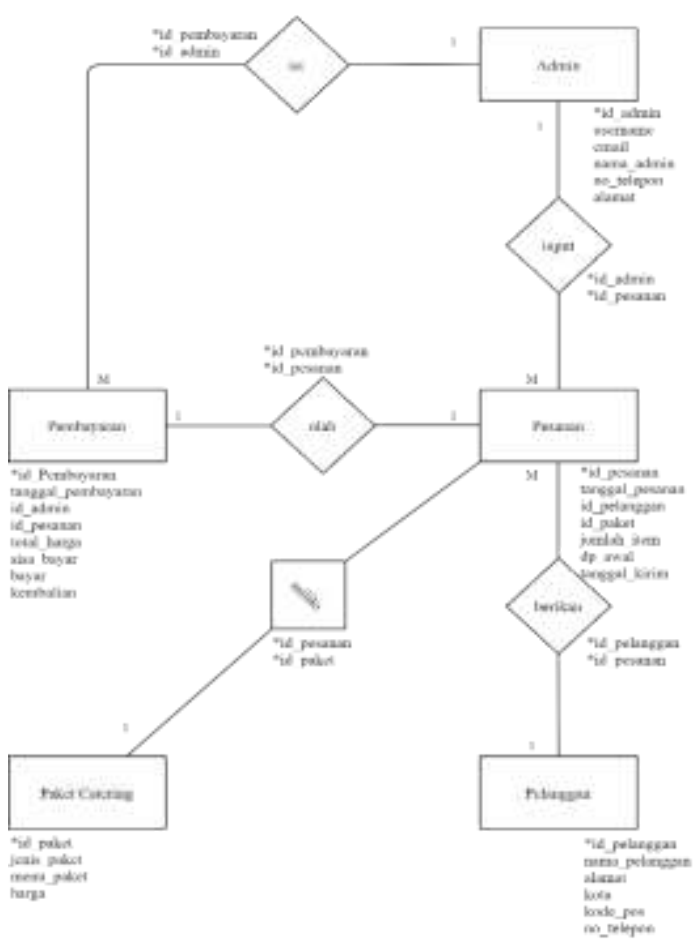

Gambar 3. ERD (Entity Relationship Diagram)

Dibawah ini adalah Transformasi ERD ke LRS yaitu sesuatu aktivitas untuk membentuk data dari diagram ikatan entitas ke sesuatu LRS. Transformasi ini dibikin bersumber pada ikatan entitas dengan mencermati tingkatan ikatan( Cardinality) dari ikatan entitas tersebut (Andah, 2020).

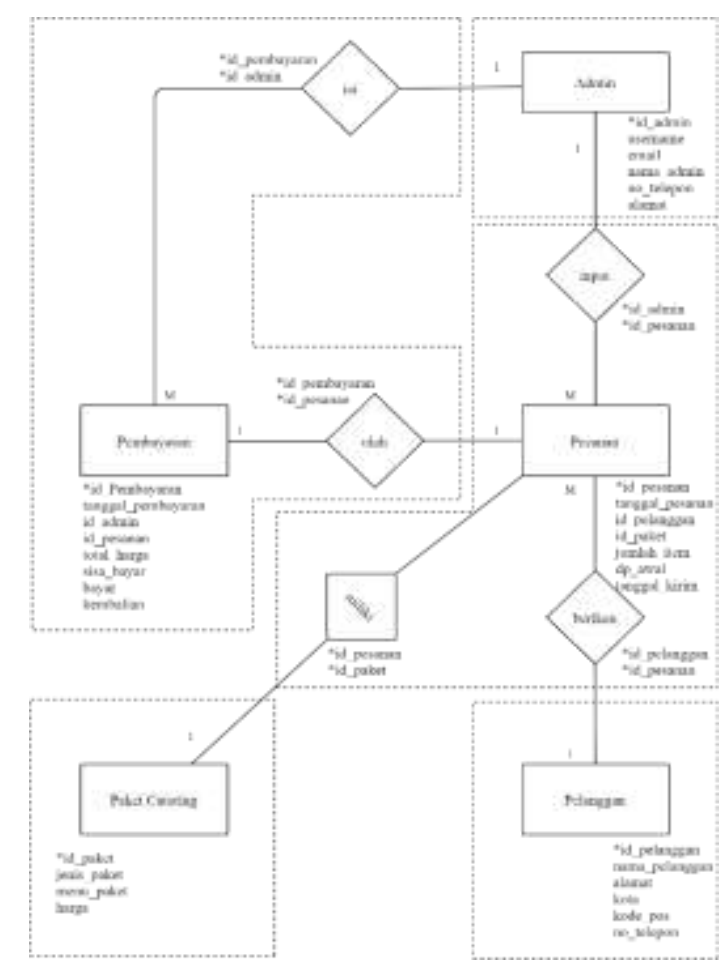

Gambar 4. Transformasi ERD ke LRS 
LRS (Logical Relational Structure) juga terdiri dari hubungan antara tipe record yang dapat dikonversikan ke LRS. Metode tersebut diawali dengan ERD dan langsung dikonversikan ke LRS, perbedaan LRS dengan diagram-ER nama tipe record berada di luar kotak field tipe record di tempatkan (Sari \& Probonegoro, 2021).

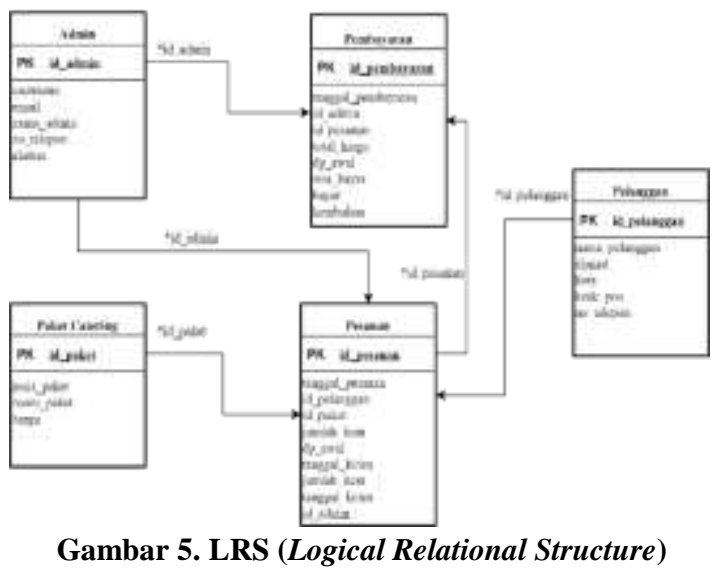

Berdasarkan hasil dan pembahasan yang sudah dijelaskan diatas, penulis membuat sistem informasi pemesanan catering pada Buna Homemade berbasis java. Berikut adalah tampilan layar dan hasil pengujian pada software program yang telah dibuat dengan bahasa pemrograman Java:

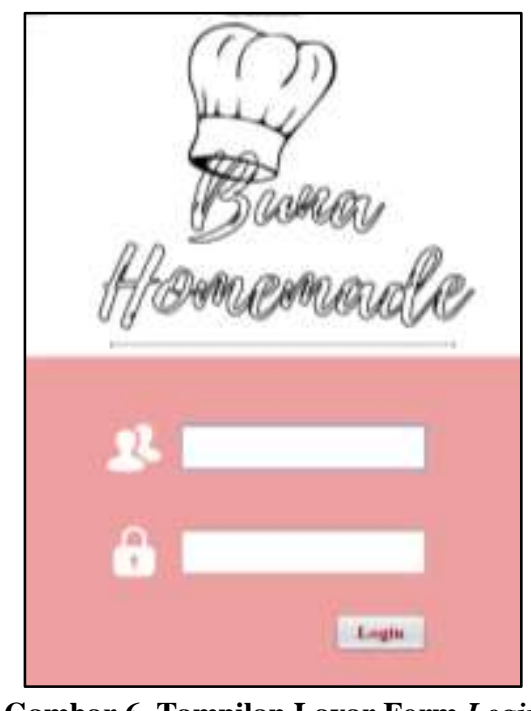

Gambar 6. Tampilan Layar Form Login

Pada tampilan menu login terdapat username dan password sebagai kata kunci sebelum masuk ke form utama yang wajib admin isi sebelum mengakses program ini.

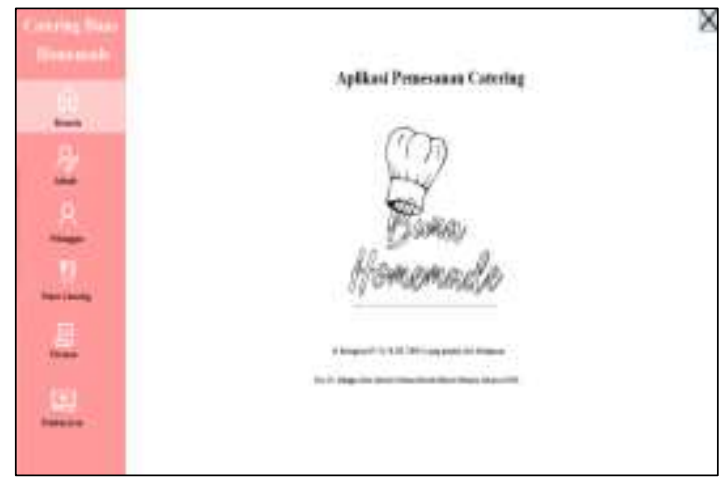

Gambar 7. Tampilan Layar Beranda

Tampilan layar menu beranda menampilkan menu data yang nantinya akan digunakan untuk menginput data Admin, Pelanggan, Paket Catering, Pesanan, dan Pembayaran. Pada layar menu utama terdapat alamat Buna Homemade serta terdapat logo Buna Homemade.

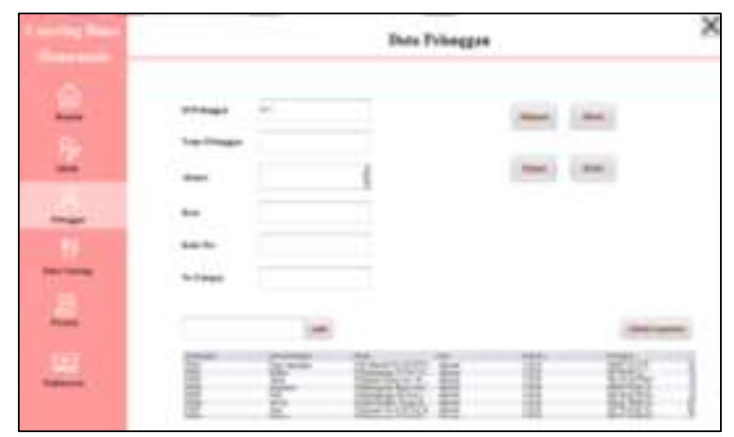

Gambar 8. Tampilan Layar Form Pelanggan

Tampilan layar menu pelanggan digunakan untuk menginput data pelanggan yang akan melakukan pemesanan catering pada Buna Homemade. Pada menu pelanggan terdapat id pelanggan, nama pelanggan, alamat pelanggan, kota, kode pos, dan no telepon pelanggan yang nantinya bisa dihubungi oleh admin.

Tampilan menu pelanggan terdapat tombol simpan untuk mendata data pelanggan, tombol ubah untuk mengubah data pelanggan, tombol hapus untuk menghapus data pelanggan, tombol batal untuk membatalkan penambahan data pelanggan, tombol $\mathrm{X}$ digunakan untuk keluar dari menu, dan tombol cetak laporan untuk mencetak data pelanggan. 


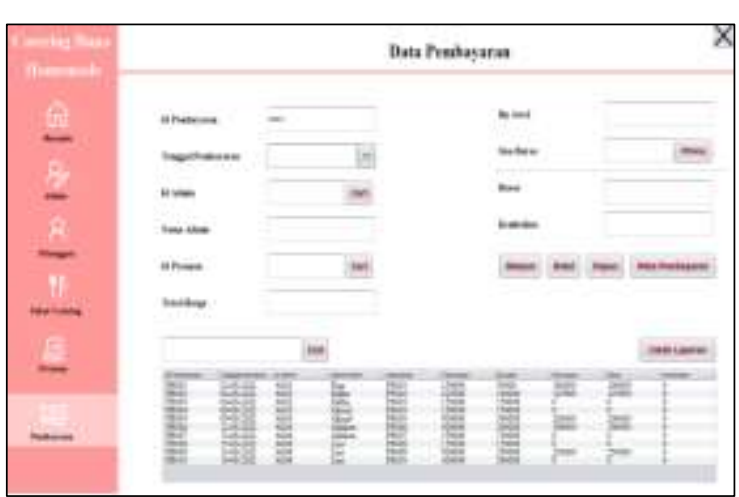

Gambar 9. Tampilan Layar Form Pembayaran

Tampilan layar menu pembayaran digunakan untuk menginput data pembayaran yang didata oleh admin sesuai dengan pesanan pelanggan. Pada menu pembayaran terdatap id pembayaran, tanggal pembayaran, nama admin yang menginput data pemesanan pelanggan sudah didata sebelumnya pada menu admin, id pesanan, total harga, dp awal, sisa bayar terhitung dari total harga dan dp awal yang sebelumnya sudah didata pada menu pesanan, bayar, dan kembalian.

Tampilan menu pembayaran terdapat tombol simpan digunakan untuk mendata data pembayaran, tombol hapus digunakan untuk menghapus data pembayaran, tombol batal untuk membatalkan pendataan pembayaran, tombol X digunakan untuk keluar dari menu, nota pembayaran untuk cetak nota pembayaran, dan tombol cetak laporan untuk mencetak data pembayaran.

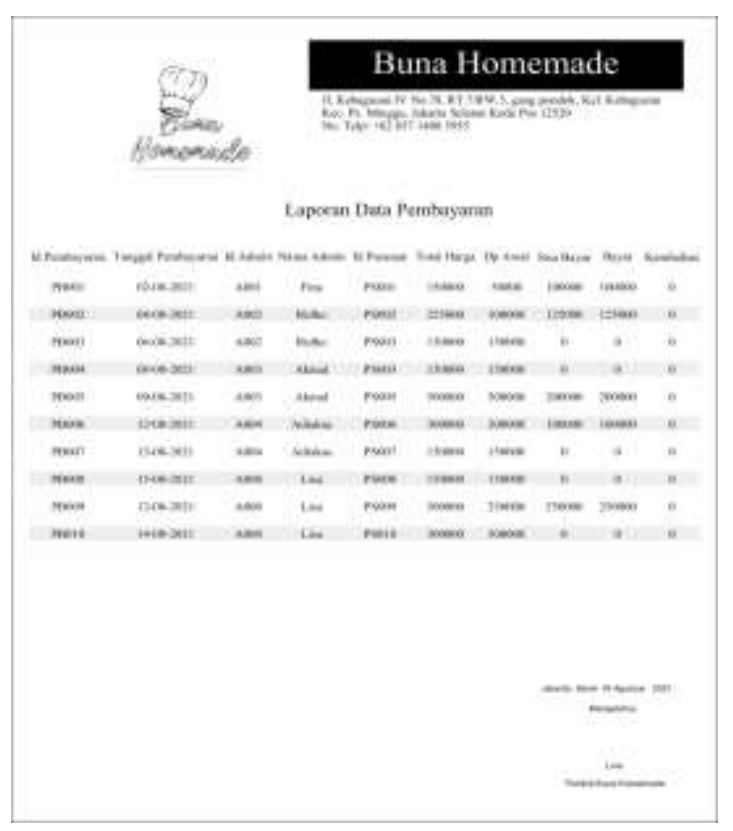

Gambar 10. Tampilan Laporan Data Pembayaran
Tampilan layar ini menampilkan menu cetak laporan yang ada pada data Pembayaran digunakan untuk mencetak laporan data Pembayaran. Tampilan ini dibuat menggunakan Jasper Report, data yang muncul pada tampilan ini merupakan data yang diambil dari database untuk mengetahui laporan data Pembayaran.

Hasil penelitian perancangan sistem informasi pemesanan catering pada Buna Homemade dibuat dengan netbeans, pada aplikasi tersebut terdapat data admin, pelanggan, paket catering, pemesanan, pembayaran, dan laporan. Berikut adalah table hasil penelitian:

Table 1. Tabel Hasil Penelitian

\begin{tabular}{|c|c|l|}
\hline No. & \multicolumn{1}{|c|}{ Nama } & \multicolumn{1}{c|}{ Keterangan } \\
\hline 1. & Data Master & $\begin{array}{l}\text { Menu yang ada pada data } \\
\text { master terdiri dari data } \\
\text { admin, pelanggan, paket } \\
\text { catering, dan pesanan. Data } \\
\text { master digunakan untuk } \\
\text { menginput data konsumen } \\
\text { yang akan melakukan } \\
\text { pemesanan catering } \\
\text { dilakukan oleh admin }\end{array}$ \\
\hline 2. & Transaksi & $\begin{array}{l}\text { Pada menu pembayaran } \\
\text { digunakan untuk menginput } \\
\text { data pembayaran yang } \\
\text { sebelumnya sudah didata } \\
\text { oleh admin sesuai dengan } \\
\text { pesanan pelanggan }\end{array}$ \\
\hline 3. & Laporan & $\begin{array}{l}\text { Untuk cetak laporan yang ada } \\
\text { pada menu admin, pelanggan, } \\
\text { paket catering, pesanan, dan } \\
\text { pembayaran digunakan untuk } \\
\text { mencetak laporan data yang } \\
\text { dibuat menggunakan Jasper } \\
\text { Report }\end{array}$ \\
\hline
\end{tabular}

\section{SIMPULAN DAN SARAN}

Berdasarkan penilitian dengan adanya perancangan sistem informasi pemesanan catering pada Buna Homemade yang berlokasi di Jl. Kebagusan IV ini dapat berjalan dengan baik, aplikasi ini diharapkan akan mempermudah dalam hal pemesanan catering. Dari penelitian yang penulis lakukan, maka penulis membuat simpulan berdasarkan rumusan masalah, yaitu sistem informasi pembuatan laporan pembayaran dan 
pemesanan untuk mendukung pemesanan catering agar lebih cepat, tepat dan akurat dalam proses pemesanan.

Berdasarkan hasil penelitian, kesimpulan, dan batasan masalah yang telah dikemukakan oleh penulis, maka penulis memberi saran sebagai berikut: Sistem ini kedepannya bisa dikembangkan lagi ke aplikasi android sehingga pemesanan catering bisa langsung dari rumah tanpa datang ke tempat catering.

\section{DAFTAR PUSTAKA}

Al Hadad, R. S. (2020). Sistem Informasi Pemesanan Katering Berbasis Web Pada Qita Catering Cimahi. Universitas Komputer Indonesia.

Andah, B. D. (2020). Penerapan Electronic Customer Relationship Management (E-CRM) dalam Upaya Meningkatkan Pendapatan Penjualan pada PT. Cipta Aneka Buah. IDEALIS: InDonEsiA JournaL Information System, 3(1), 20-25.

Fatoni, A., \& Dwi, D. (2016). Rancang bangun sistem extreme programming sebagai metodologi pengembangan sistem. PROSISKO: Jurnal Pengembangan Riset Dan Observasi Sistem Komputer, 3(1).

Fridayanthie, E. W., \& Mahdiati, T. (2016). Rancang Bangun Sistem Informasi Permintaan Atk Berbasis Intranet (Studi Kasus: Kejaksaan Negeri Rangkasbitung). Jurnal Khatulistiwa Informatika, 4(2).

Gunawan, I. (2013). Metode penelitian kualitatif. Jakarta: Bumi Aksara, 143.

Hutahaean, J. (2015). Konsep sistem informasi. Deepublish.

Sari, L. I., \& Probonegoro, W. A. (2021). Sistem Informasi Pelayanan Jasa Laundry Berbasis Desktop Pada Sun Laundry Pangkalpinang. INFORMANIKA, 7(01).

Sutabri, T. (2012). Analisis sistem informasi. Penerbit Andi.

Tabrani, M. (2018). Penerapan Metode Waterfall Pada Sistem Informasi Inventori Pt. Pangan Sehat Sejahtera. Jurnal Inkofar, I(2).

Tabrani, M., \& Aghniya, I. R. (2019). Implementasi Metode Waterfall Pada Program Simpan Pinjam Koperasi Subur Jaya Mandiri Subang. Jurnal Interkom: Jurnal Publikasi Ilmiah Bidang Teknologi Informasi Dan Komunikasi, 14(1), 44-53. 